\title{
A Brief Analysis of the Piano Music, "On the Mountain the Red Flowers are All Open"
}

\author{
Juan ZHANG
}

\author{
No.18 of dianzi road Yanta District Xi'an Shaanxi province, Music Department of Xi'an Shiyou \\ University \\ 494068277@qq.com
}

Keywords: "On the mountain the red flowers are all open" ,Playing and handling; Emotional grasp

\begin{abstract}
On the mountain the red flowers are all open”, from wang jianzhong's " the northern shaanxi' s beloved five", with light bright melody for the song, abundant harmonic color, distinctive performance and music expressive force, depicts the scene that the northern shanxi people looking forward to the red army, welcome to the red army, and the army and the people are as inseparable as fish and water. Mr Wang's combination of China's music and western instrumental music has both retained the unique Chinese flavor and the grandeur of western instrumental music. Rich harmonic color, the author's exquisite structure arrangement, layer of progressive emotion, are the highlights of this work. In addition to the introduction of author and background, this paper also analyzes the composition, technique and emotion of the works. I hope that can help some people.

The piano music "On the mountain the red flowers are all open" is based on the revolutionary song of the same name that has been circulated in northern shanxi, and the unique flavor of music of Chinese nation is combined with the grandeur of western instrumental music. I have made a brief analysis on the background, style structure, playing skills and emotional expression of the works by consulting a large amount of relevant information. Hopefully, this thesis will give you some insight into the work and help you to play it.
\end{abstract}

\section{Background}

Background: in early 1934, the communist party of China (BeiFangJu sent people to the border but so do dungans review the work of local, they think of shanbei soldiers walk is the right route of socialism, some patriotic loyal guard jailed even abusing, until October 1935, chairman MAO's coming to save zhi-dan liu and other patriotic, to disperse the haze shrouded over but so do dungans base.

GuanHeYan creation background: musicians and the music creation home to northern shaanxi tour, to circulate in the Anti-Japanese War of the local folk songs for sorting, produced a eulogized revolution team and the great leader chairman MAO arrived in northern shaanxi, gongs, uninhibited passion of shaanxi people meet their songs, namely the red flower red.

\section{Composition Analysis}

The piano adaption "On the mountain the red flowers are all open" is the piano music of a complex trilogy, which is based on the ethnic tonal business. Its structure is:

The work introduction to ragtime, a total of eight sections, with demisemiquaver pentatonic scale type arpeggios and long tone is given priority to, with a grace note playing in four octaves, rhythm free and relax, ended in the tonic rich sense of belonging; The first part is the theme of the whole song, which is warm and singing. The main F commercial is transferred. A parallel double body, subject and the a1 is the change of the latter is the former repeat, it will be the basis of a melody tone of voice changes for chords or octave, changed or unchanged melody accompaniment texture, making music and sound more colorful, emotion gradually heating up, show the northern shaanxi people looking forward to the arrival of the red army eager mood; 43 section (32) is derived on the tone of connection part, the section a strong emotional color, as if is warm earthy shaanxi people are banging drums to meet the arrival of the red army; The center is a mental fast board, made up of $b$ 
themes and its three variations. The first appearance of the theme of $b$, music atmosphere was joyful and filled with the feeling of jumping; It's the first time variation and the theme to the left hand takes the form of single tone, the second variation of the main theme to the right hand to play, a series of passing notes, auxiliary notes to join the phrase becomes more dense compact; The third variation of the chord has made the theme more important. The same theme, different processing techniques, the alternation of the left and right hand melodies and the superposition of the sound colors can reveal the ingenious conception of the author and the originality of arranging the structure of the music. The representation of the first part is the reappearance of the first part, which is the same as the main melody of the presentation part, which forms the structure of the first and final echo.

\section{Performance Skills and the Emotional Color}

\section{Performance Skills}

Introduction (1-8 section) : is a free ragtime, continuous demisemiquaver is based on the pentatonic scale arpeggio from weak to strong, from slow to quick like imitating from far to near, melodious flute playing this time to focus on every note of clarity, each finger independence, alternate connection to close with your left and right hand, and to coherent nature between the notes. In practice, I suggest that you take each group of arpeggio and practice it separately, then practice it in sections, and then play the whole lead.

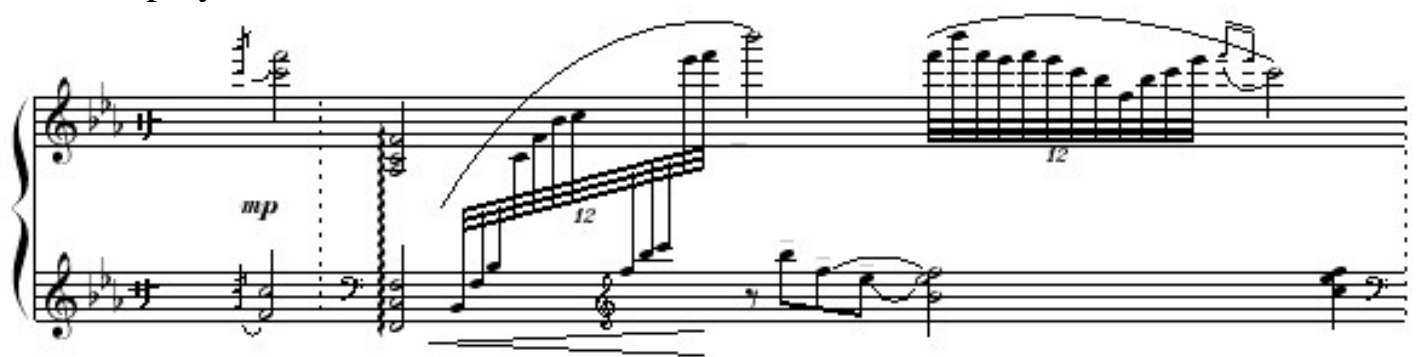

Eg 1

Part 1 (9-31) : the light and clear main melody enters slowly, the use of small and chic notes in the 10th bar, gives a refreshing feeling. When playing this section, you need to control your fingers and touch the keys with your fingertips. When playing, pay special attention to the expression terms on the spectrum. The second sentence can be slightly weakened on the basis of the first sentence, making the two sentences form obvious strong and weak contrast.
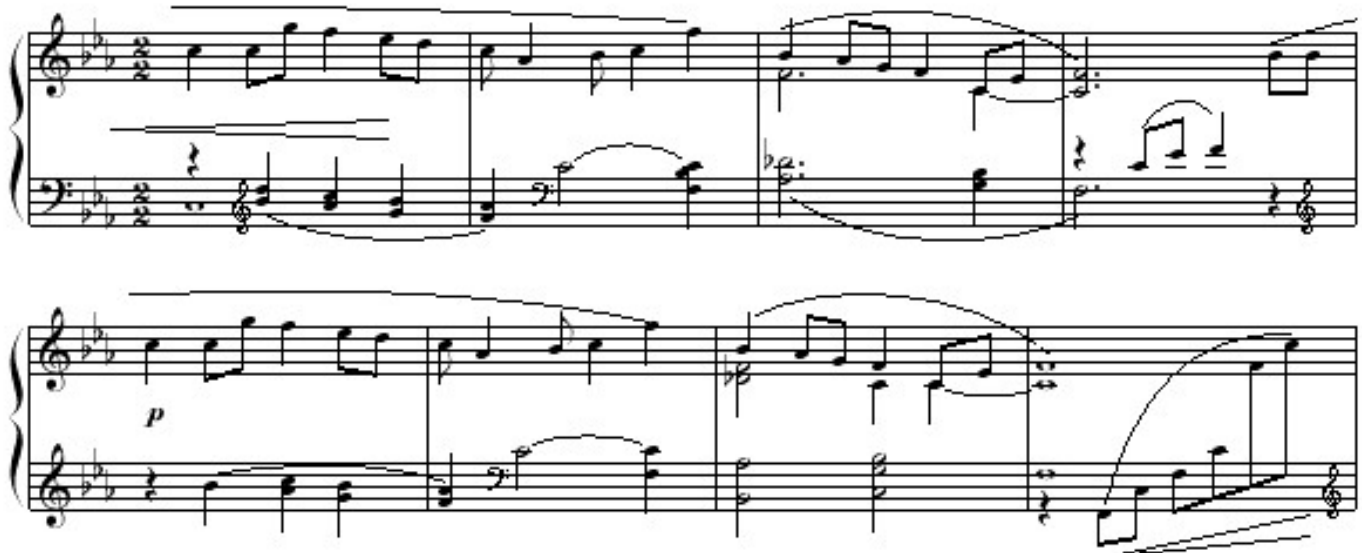

Eg2

A1 is a variation of a theme. Chords and octaves appear in the high octave range to make the music instantly warm. For example 3, when playing chords and octaves, the arm must be relaxed, keeping the sound down and keeping it clean, and try to be quick when looking for a sound. Pedal 
to change also should timely, do not mop water. The 3-2 beat and 2/2 beat requires us to be clear about the beat. This paragraph can be practiced with each of the phrases as the unit first break up and practice in the hands together, so as to maintain the sense of the phrase, and maintain the player's familiarity with the song.

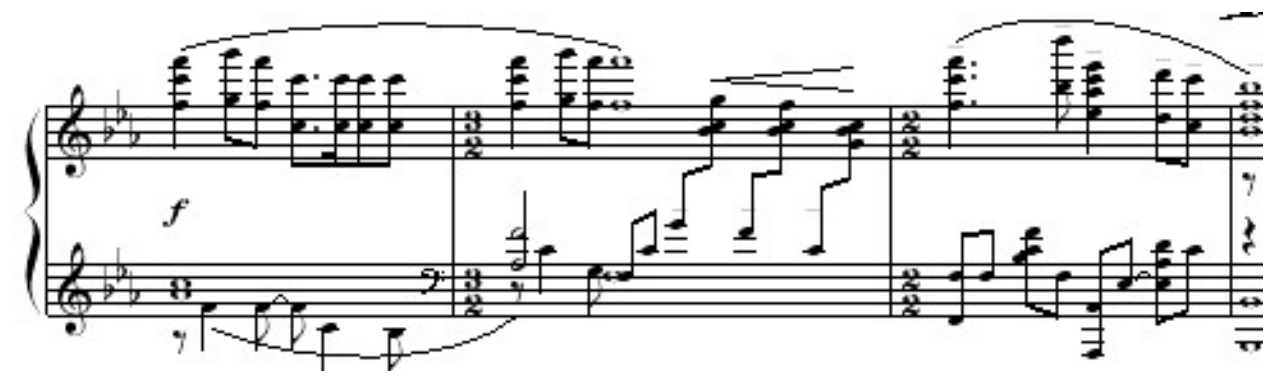

Eg 3

Connection part (32 - section 43) : this section emotional color is extremely strong, want to play very smart and active, right hand the sound a little heavier, fingers to has the explosive force, pay attention to the score of the accent sign, chord to fall together, neat and agile, and pay attention to grasp the rhythm. This part of the practice suggests that you practice the chords with one hand and then practice the harmony of the two hands together with the right and left hands. Finally, you can speed up the range of your abilities.

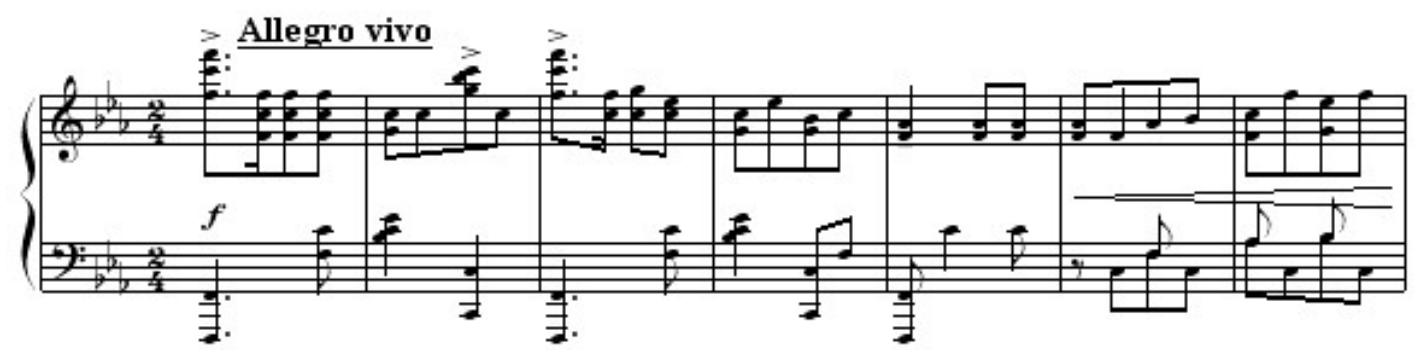

$\operatorname{Eg} 4$

Middle (44-140) : consists of b subject and its three variations. Each variation of excessive is from weak to strong, progressive transformation, such as PuLi 5, Mr Wang Jianzhong between two variation with channel mode scales completed from low to high, strength of emotion from weak to strong, cohesion is very smooth and natural. This part should be taken out of the excessive sentence to practice the running of the scale, and then to connect with the theme, so that when playing, it will be too much natural and smooth.

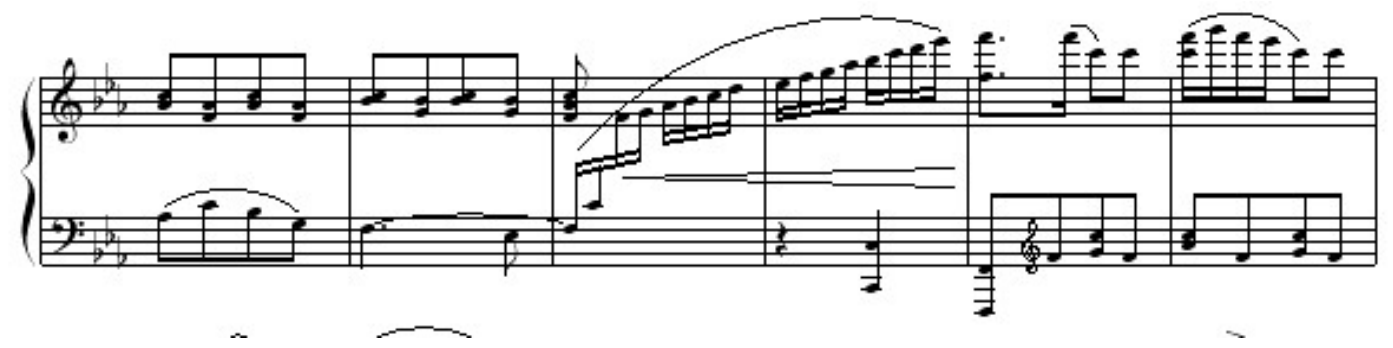

Eg 5

Reappearance division (section 141-164) : at the end of the time, the speed of the performance can be slowed properly, so that each note is full, and the feeling is sincere and exquisite. As if the camera had been switched to the original, there was still a wisp of the flute. After playing hands alternately arpeggios, vibrato section connection speed can be slow to fast, from strong to weak, a section to keep two cohesion tightness, and pay attention to the sense of complete sentences. For example , when playing, the playing is strong and weak, from weak to strong, should be relaxed, 
wrist to relax, palms to hold up, fingertips touch keys, pay attention to the full range of tone color.

\section{Style of Works}

From the melody style, the piano adaptation retains the original characteristics of the vocal music melody, on the basis of the original work of the handing down, joined the tremolo, passing notes, auxiliary notes and other series of grace note, as well as the right-hand man of alternation of this work has a certain aesthetic feeling, both the beauty of China's classical music and western music atmosphere.

In terms of structural style, the paragraph structure of the works is reasonable, and each time the variation arrangement is ingenious, the transition of sentence and sentence is very natural, and the presentation and reconstruction department echo the beginning and end of the work. Strength, speed control, every connection is just right.

From the point of harmony style, the author try to keep to a certain extent the music of the original style, with octave, chords, increase the effect of harmony, simple give a person a kind of aftertaste endless.

\section{How to Play the Work Better?}

\section{The Psychological Quality}

There are a number of factors that lead to this phenomenon during our performance, for example: invisible pressure from the audience. Inadequate preparation; To be confused after the wrong sound; Expect too much of yourself. Therefore, in playing the piano, you should first have confidence in yourself, and keep on giving yourself psychological hints. Or try to focus all your attention on the performance of music.

\section{Emotion}

Play each a tune, we want to know some basic information for this song, so as to help us better understand and play it, just like“ On the mountain the red flowers are all open” must make northern shaanxi people look forward to the red army, against the red army and the lively atmosphere of military and civilian members hold good.

\section{Pay Attention to the Rhythm}

Probe, although it is free for this song ragtime, but we also want to grasp it in the process of playing the rhythm, and strive to form spirit, tunes in the inner parts and bass USES plenty of syncopation, change the position of strong beat, it is important to note that when playing score on the strength of the mark, to grasp the syncopation of duration.

\section{Pedal Use}

There are different ways to use the pedals in the warm and cheerful work of "On the mountain the red flowers are all open”.For example, the long arpeggio of the introduction part, a whole sentence should be stamped on the pedal, so that the consistency of the music can be guaranteed to create a feeling from far to near to ethereal; The rest of us can change the pedals or a bar to change the pedals in a phrase.

\section{Conclusions}

Every music art works is the expression of the creator's heart, the catharsis of the emotion and the emotional sustenance of the listener. Jianzhong wang, Shande Ding and so on,musicianes, combined Chinese music works and western instrumentes, on the basis of Chinese national music to join the western instrumental music, the innovation of the creation of Chinese piano music have played an important role in the development of itself.

The world is a big stage, and various forms of art and culture can be displayed on this stage, seeking common ground while reserving differences and differences, so as to adapt to the trend of The Times. Mr Jianzhong Wang adaptation of“ On the mountain the red flowers are all open” let 
me appreciate the unique charm of Chinese national music, and through analyses the work make me feel the breath of revolution, as well as the northern shaanxi people's plain. The author has an admirable structure and emotional expression for the work, and hopes that by analyzing this work, we can feel the charm of national music.

\section{References}

[1]Yange Wei.30 Famous Chinese Piano Pieces [M]. People's Music Publishing House, 2004.

[2]Mingsun Zhou .Sounds and skills [J], People's Music Publishing House , 1996.

[3]Xiaohu Zhang. Five tone mode and harmony method [M].People's Music Publishing House , 1987.

[4]Qiankun Zhang. The interpretation of Chinese piano music [M]. Sichuan literature and Art Publishing House ,2007.

[5]Xiaosheng Zhao. The way of piano playing [M]. Shanghai World Book Inc, 1999. 